\title{
Determination of simple carbohydrates in beer using SPME, on fiber derivatization and gas chromatography mass spectrometry
}

\author{
*D’Auria, M., Emanuele, L., Racioppi, R. and Stefanizzi, N. \\ Dipartimento di Scienze, Università della Basilicata, Via dell'Ateneo Lucano 10, 85100 Potenza, Italy
}

\author{
Article history: \\ Received: 2 February 2020 \\ Received in revised form: 9 \\ March 2020 \\ Accepted: 11 March 2020 \\ Available Online: 1 April \\ 2020
}

Keywords:

Beer,

Carbohydrates,

Gas chromatography,

Mass spectrometry,

Solid phase microextraction,

On fiber derivatization

\begin{abstract}
Fermentable sugars directly contribute to the sweetness of beer, whereas carbohydrates with more than four glycosyl units can be beneficial to the perception of beer in that they contribute to body or mouthfeel. GC/MS has not been widely used for the analysis of carbohydrate contents in beer. The analysis of beer by using L-SPME, on fiber derivatization with bis(trimethylsilyl) trifluoroacetamide (BSTFA) and GC-MS showed the presence of some carbohydrates (D-arabinose, $\beta$-D-arabinopyranose, $\mathrm{D}$-galactose, $\mathrm{D}$ xylose, and D-mannose) never detected in beer. The analysis of three different types of beer showed that the presence of these carbohydrates can represent a significant part of the total amount of carbohydrates present in the beer.
\end{abstract}

DOI:

https://doi.org/10.26656/fr.2017.4(4).055

\section{Introduction}

Beer is a fermented beverage made from malted grains, hops, yeast, and water (De Keukeleire, 2000; Duarte et al., 2003). Major beer components are water, ethanol, and carbohydrates comprising fermentable sugars (i.e., fructose, maltose, and maltotriose), as well as glucose oligosaccharides (Brandolini et al., 1995). Fermentable sugars directly contribute to the sweetness of beer, whereas carbohydrates with more than four glycosyl units can be beneficial to the perception of beer in that they contribute to body or mouthfeel (Corradini et al., 1997).

The analysis of carbohydrates is generally carried out by high-performance liquid chromatography (HPLC), which can provide not only the qualitative analysis but also the quantitative determination (Constant et al., 1995; Wei and Ding, 2000). The carbohydrate content in beer is approximately $3-5 \%$, while in some strong beers or malt beers it may be considerably higher (Belitz et al., 2004). The carbohydrate content in beer can be an important element to estimate the impact of this beverage on human feeding (Bamforth, 2005).

The main chromatographic systems used for underivatized carbohydrates can be generalized as anionexchange column with water containing bases or salts as the eluent (Torto et al., 1995); cation-exchange column with water as the eluent (Clement et al., 1992); alkylbonded silica gel column with water as the eluent (Rajakyla, 1986); and amine-bonded silica gel column with water-acetonitrile as the eluent (Macrae and Dick, 1981; Macrae et al., 1982; Nikolov et al., 1985; Clement et al., 1992; Ferreira and Ferreira, 1997; Ferreira et al., 1998).

In the brewing industry, specific chromatographic methods have been developed in order to evaluate these compounds (Coquet et al., 1994; Lehtonen and Hurme, 1994; McLinn et al., 1994; Madigan et al., 1996; Castellari et al., 2001; Cortacero-Ramirez et al., 2004; Nogueira et al., 2005).

Solid phase microextraction (SPME) has shown to be a powerful instrument for the determination of volatile organic compounds (VOCs) (Pawliszyn, 1997). SPME is an extraction method involving adsorption of analytes on a solid phase deposited on a silica fiber. The extraction of the components is achieved either by immersing the fiber into the liquid to be analyzed (LSPME), or by simple contact with its headspace under static conditions (SHS-SPME). In the past, we reported several applications of SPME in the analysis of VOCs from truffles (Mauriello et al., 2001; Mauriello et al., 2004), olive oil (Bentivenga et al., 2001; Bentivenga et al., 2002; Bentivenga, D'Auria, Mauriello et al., (2004), saffron (D'Auria, Mauriello and Rana, 2004; D'Auria et 
al., 2006), horseradish (D'Auria, Mauriello and Racioppi, 2004), honey (Bentivenga, D'Auria, Fedeli et al., 2004), thymus (D'Auria et al., 2005), oregano (D'Auria et al., 2005), lavender (D'Auria et al., 2005), and cheese (D'Auria et al., 2006).

In this paper, we reported our results obtained using L-SPME on beer coupled with GC/MS after on-fiber derivatization of the analytes.

\section{Materials and methods}

SPME extractions were performed using a $60 \mu \mathrm{m}$ carbowax-divinylbenzene fiber obtained from Supelco (Milan, Italy). The $10 \mathrm{~mL}$ samples were places in $20 \mathrm{~mL}$ vials with septa and agitation was performed using magnetic stirring. All the extractions were conducted at ambient temperature for 30 mins and were agitated using magnetic stirring. Bis(trimethylsilyl) trifluoroacetamide (BSTFA) was obtained by Aldrich (Milan, Italy). To a $20 \mathrm{ml}$ vial sealed with a septum, $100 \mu \mathrm{L}$ of BSTFA were added. Derivatization was performed by piercing the septum with the SPME needle and exposing the fiber to the contained vapor for 60 mins at $70^{\circ} \mathrm{C}$. The fiber was then introduced into the injection port of a HP6890 plus gas-chromatograph equipped with a Phenomenex Zebron ZB-5 MS capillary column (30 m x $0.25 \mathrm{~mm}$ ID x $0.25 \mu$ $\mathrm{m}$ film thickness). As for detector, a HP5973 mass selective detector (mass range: 15-800 amu; scan rate: 1.9 scans/s; EM voltage: 1435 ) was used while helium at $0.8 \mathrm{ml} / \mathrm{min}$ was used as the carrier gas. The injection port, equipped with glass insert (internal diameter 0.75 $\mathrm{mm}$ ) was splitless at $250^{\circ} \mathrm{C}$. The desorption time of 1.0 min was used. The detector was maintained at $230^{\circ} \mathrm{C}$. The oven was maintained at $100^{\circ} \mathrm{C}$ for $5 \mathrm{mins}$, then the temperature increased until $250^{\circ} \mathrm{C}\left(30^{\circ} \mathrm{C} / \mathrm{min}\right)$; then, the temperature increased until $300^{\circ} \mathrm{C}\left(3^{\circ} \mathrm{C} / \mathrm{min}\right)$; finally, this temperature was maintained for 5 mins. All the analyses were performed in triplicate. The chromatograms obtained from the total ion current (TIC) were integrated without any correction for coelutions and the results were expressed in arbitrary surface unites (asu). All the peaks were identified from their mass spectra by comparison with spectra in Wiley6N and NIST98 libraries.

\section{Results and discussion}

The beer samples were analyzed by using L-SPME technique followed by on-fiber derivatization by using bis(trimethylsilyl) trifluoroacetamide. The adsorbed analytes were analyzed using a GS/MS apparatus (Okeyo and Snow, 1998). Figure 1 shows the typical chromatogram we obtained. We can see that we were able to identify only some components while most of the compounds were not identified. We identified the presence of D-arabinose, $\beta$-D-arabinopyranose, Dgalactose, D-xylose, and D-mannose. In Figure 2, the mass spectra registered for these compounds as trimethylsilyl derivatives was shown. The identification was obtained by comparison with both Wiley6 mass spectra library and pure samples. Furthermore, we were not able to identify the presence of fructose, maltose, maltotreose, and maltotetrose, the most important carbohydrates present in the beer (Coquet et al., 1994; Lehtonen and Hurme, 1994; McLinn et al., 1994; Madigan et al., 1996; Castellari et al., 2001; CortaceroRamirez et al., 2004; Nogueira et al., 2005). It is noteworthy that, in our knowledge, those compounds (Darabinose, $\beta$-D-arabinopyranose, D-galactose, D-xylose, and D-mannose) were not identified in beer until now.

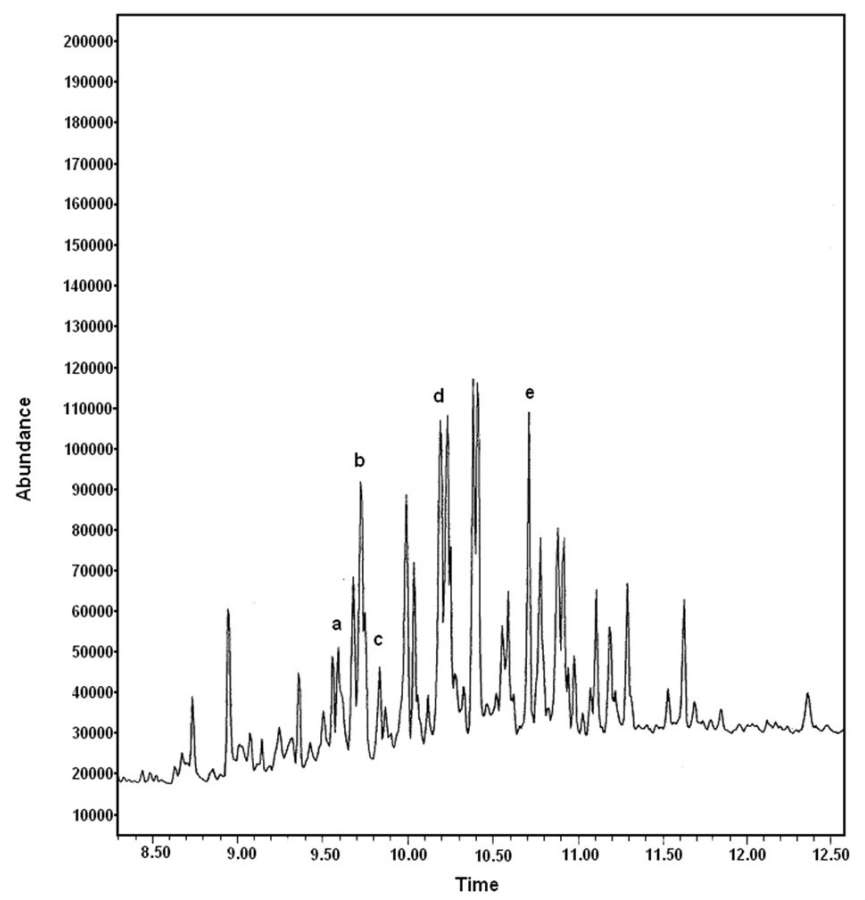

Figure 1. GC-MS analysis of a beer; a) $\beta$-D-arabinopyranose, b) D-arabinose, c) D-galactose, d) D-xylose, e) D-mannose.

Figure 3 reports the calibration curves for the five carbohydrates identified. A good calibration curve optimizing the absorption conditions was obtained. We observed that stirring of the samples needed for obtaining good results. Furthermore, we optimized also the post-derivatization procedure, where the time of exposition of the fiber and temperature were controlled.

On the basis of these results, we determined the concentration of these carbohydrates in three types of beer. We tested a lager, a pilsner, and a malt beer. The results are reported in Table 1.

Only the pilsner beer did not show the carbohydrates we analyzed. The lager beer showed $471 \mathrm{mg} / \mathrm{L}$ of these carbohydrates while the malt beer showed $202 \mathrm{mg} / \mathrm{L}$ for four carbohydrates. It did not show D-mannose. 

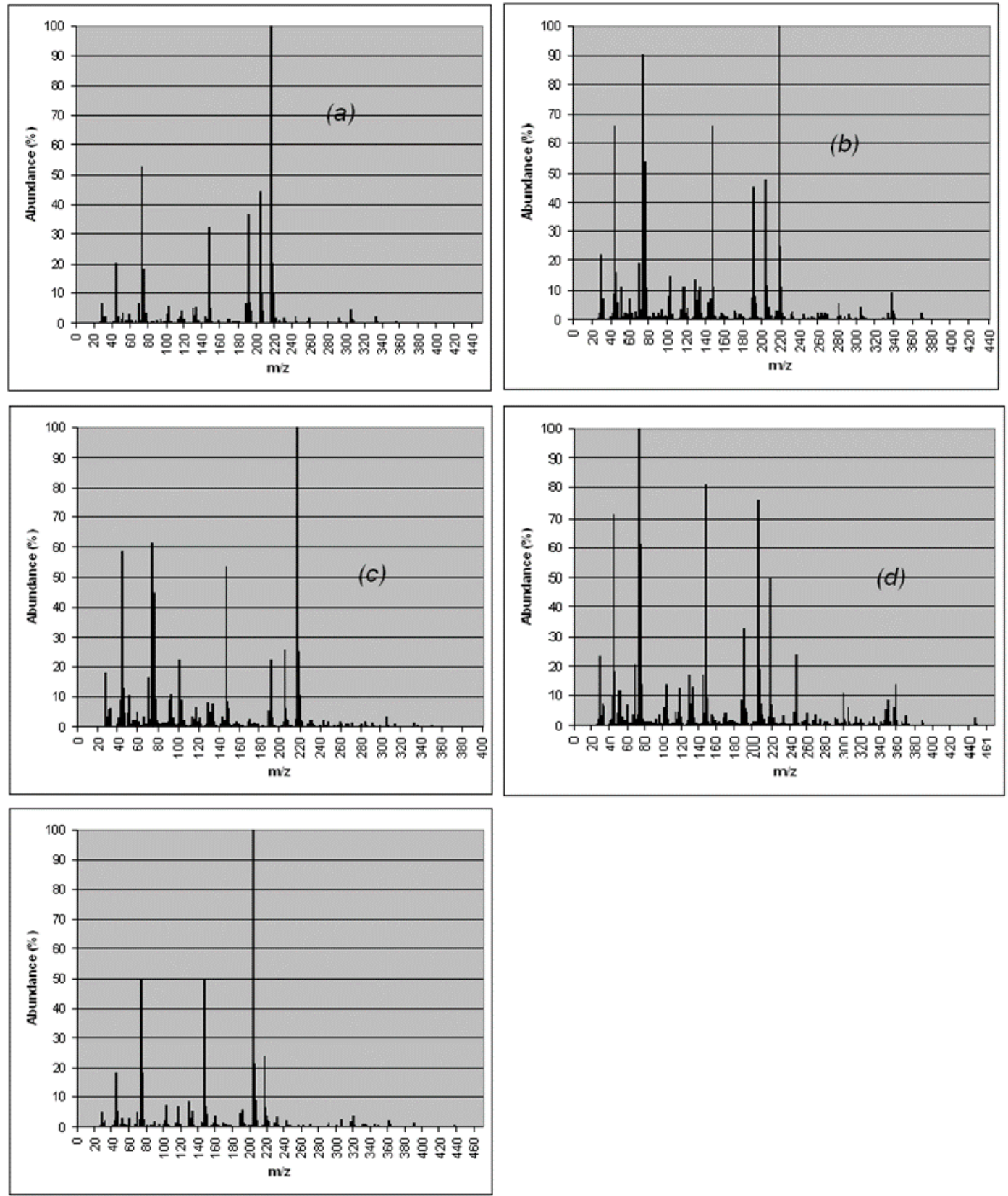

Figure 2. Mass spectra of tetrakis-O-trimethylsilyl derivatives of a) D-arabinose, b) b-D-arabinopyranose, c) D-galactose, d) Dxylose, and e) D-mannose found in beer samples.

Table 1. Carbohydrate amounts in beer.

\begin{tabular}{lccc}
\hline Carbohydrate & Lager $(\mathrm{mg} / \mathrm{L})$ & Malt $(\mathrm{mg} / \mathrm{L})$ & Pilsner $(\mathrm{mg} / \mathrm{L})$ \\
\hline D-Arabinose & $66 \pm 3$ & $37 \pm 2$ & --- \\
$\beta$-D-Arabinopyranose & $31 \pm 2$ & $13 \pm 2$ & --- \\
D-Galactose & $32 \pm 2$ & $68 \pm 3$ & --- \\
D-Xylose & $142 \pm 4$ & $84 \pm 3$ & --- \\
D-Mannose & $200 \pm 4$ & --- & --- \\
\hline
\end{tabular}



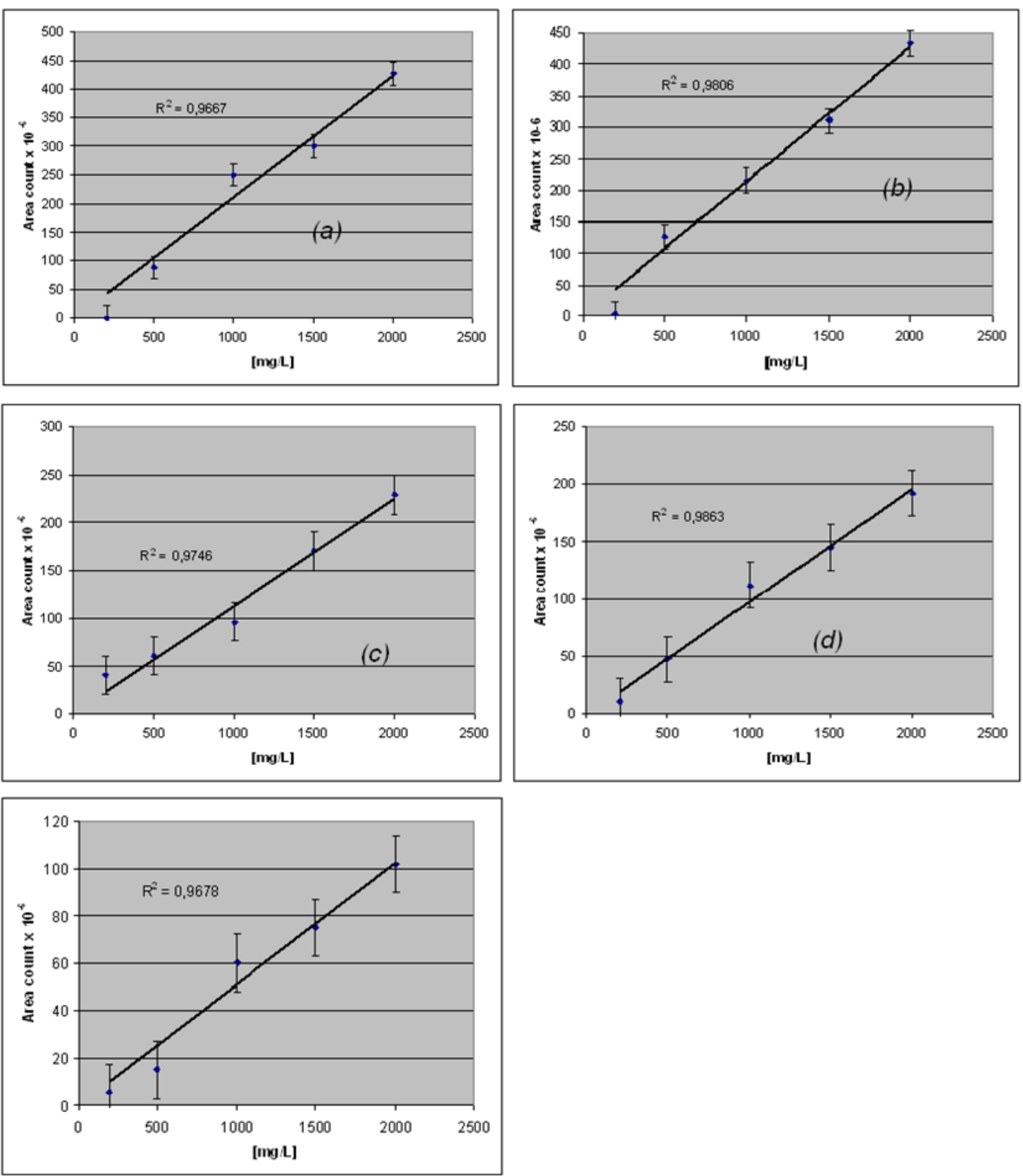

Figure 3. Calibration curves for a) D-arabinose, b) b-D-arabinopyranose, c) D-galactose, d) D-xylose, and e) D-mannose.

In conclusion, we have shown that SPME can be a useful method for the determination of some minor components of the beer. We identified the presence of five carbohydrates never detected before. The concentration of these carbohydrates is in the range $0.2-$ $0.5 \mathrm{~g} / \mathrm{L}$ and then they represent ca. $10 \%$ of the total carbohydrate amount in beer (Belitz et al., 2004).

\section{References}

Bamforth, C.W. (2005). Beer, carbohydrates and diet. Journal of the Institute of Brewing, 111(3), 259-264. https://doi.org/10.1002/j.2050-0416.2005.tb00681.x

Belitz, H.D., Grosch, W. and Schieberle, P. (Ed.) (2004). Food chemistry., p. 902. Berlin: Springer. https:// doi.org/10.1007/978-3-662-07279-0

Bentivenga, G., D'Auria, M., De Bona, A. and Mauriello, G. (2002). On the flavor of virgin olive oil. Rivista Italiana delle Sostanze Grasse, 79, 101105.

Bentivenga, G., D’Auria, M., De Luca, E., De Bona, A. and Mauriello, G. (2001). The use of SPME-GC-MS in the analysis of flavor of virgin olive oil. Rivista Italiana delle Sostanze Grasse, 78, 157-162.

Bentivenga, G., D’Auria, M., Fedeli, P., Mauriello, G. and Racioppi, R. (2004). SPME-GC-MS analysis of volatile organic compounds in honey from Basilicata. Evidence for the presence of pollutants from anthropogenic activities. International Journal of Food Science and Technology, 39(10), 1079-1086. https://doi.org/10.1111/j.1365-2621.2004.00889.x

Bentivenga, G., D’Auria, M., Mauriello, G., Racioppi, R. and Viggiani, L. (2004). Characterization of virgin olive oils from Basilicata by using ${ }^{1} \mathrm{H}-\mathrm{NMR}$ and SPME-GC-MS. Rivista Italiana delle Sostanze Grasse, 81, 86-89.

Brandolini, V., Menziani, E., Mazzotta, D., Cabras, P., Tosi, B. and Lodi, G. (1995). Use of AMD-HPTLC for carbohydrate monitoring in beers. Journal of 
Food Composition and Analysis, 8(4), 336-343. https://doi.org/10.1006/jfca.1995.1028

Castellari, M., Sartini, E., Spinabelli, U., Riponi, C. and Galassi, S. (2001). Determination of carboxylic acids, carbohydrates, glycerol, ethanol, and 5-HMF in beer by high-performance liquid chromatography and UV-refractive index double detection. Journal of Chromatographic Science, 39(6), 235-238. https:// doi.org/10.1093/chromsci/39.6.235

Clement, A., Young, D. and Brechet, C. (1992). Simultaneous identification of sugars by HPLC using evaporative light scattering detection (ELSD) and refractive index (RI). Application to plat tissues. Journal of Liquid Chromatography, 15(5), 805-817. https://doi.org/10.1080/10826079208018836

Constant, M., Hancock, I., Hassinger, T., Krynicki, L., McCarthy, S., Sadler, A., Schwarz, P., Smith, P., Uchida, M., Wehmeier, C. and Burkhardt, R. (1995). Total carbohydrates in beer by HPLC. Journal of American Society of Brewing Chemists, 48(4), 153155. https://doi.org/10.1094/ASBCJ-48-0153

Coquet, A., Haerdi, W., degli Agosti, R. and Veuthey, J.L. (1994). Determination of sugar by liquid chromatography with post-column catalytic derivatization and fluorescence detection. Chromatographia, 38, 12-16. https:// doi.org/10.1007/BF02275720

Corradini, C., Canali, G., Cogliandro, E. and Nicoletti, I. (1997). Separation of alditols of interest in food products by highperformance anion-exchange chromatography with pulsed amperometric detection. Journal of Chromatography A., 791(1-2), 343-349. https://doi.org/10.1016/S0021-9673(97) 00827-3

Cortacero-Ramirez, S., Segura-Carretero, A., CrucesBlanco, C., Hernainz-Bermudez de Castro, M. and Fernandez-Gutierrez, A. (2004). Analysis of carbohydrates in beverages by capillary electrophoresis with precolumn derivatization and UV detection. Food Chemistry, 87(3), 471-476. https://doi.org/10.1016/j.foodchem.2004.01.030

D'Auria, M., De Carlo, S. and Racioppi, R. (2006). Analisi HS-SPME-GC-MS del pecorino di Filiano. Biologi Italiani, 36(2), 49-52.

D’Auria, M., Mauriello, G., Marino, R. and Racioppi, R. (2005). Composition of volatile fraction from Thymus, Origanum, Lavandula and Acinos species. Journal of Essential Oil Bearing Plants, 8(1), 36-51. https://doi.org/10.1080/0972060X.2005.10643419

D'Auria, M., Mauriello, G. and Racioppi, R. (2004). SPME-GC-MS analysis of horseradish (Armoracia rusticana). Italian Journal of Food Science, 16(4),
487-490.

D'Auria, M., Mauriello, G., Racioppi, R. and Rana, G.L. (2006). Use of SPME-GC-MS in the study of time evolution of the constituents of saffron aroma: modifications of the composition during storage. Journal of Chromatographic Science, 44(1), 18-21. https://doi.org/10.1093/chromsci/44.1.18

D'Auria, M., Mauriello, G. and Rana, G.L. (2004). Volatile organic compounds from saffron. Flavour and Fragrance Journal, 19(1), 17-23. https:// doi.org/10.1002/ffj.1266

De Keukeleire, D. (2000). Fundamentals of beer and hop chemistry. Quimica Nova, 23, 108-112. https:// doi.org/10.1590/S0100-40422000000100019

Duarte, I.F., Godejohann, M., Braumann, U., Spraul, M. and Gil, A.M. (2003). Application of NMR spectroscopy and LC-NMR/MS to the identification of carbohydrates in beer. Journal of Agricultural and Food Chemistry, 51, 4847-4852. https:// doi.org/10.1021/jf030097j

Ferreira, I.M.P.L.V.O. and Ferreira, M.A. (1997). Simultaneous determination of sugars, uric and orotic acids in infant formulae by HPLC-UV/RI. Journal of Liquid Chromatography and Related Technologies, 20(20), 3419-3429. https:// doi.org/10.1080/10826079708005841

Ferreira, I.M.P.L.V.O., Gomes, A.M.P. and Ferreira, M.A. (1998). Determination of sugars, and some other compounds in infant formulae, follow-up milks and human milk by HPLC-UV/RI. Carbohydrate Polymers, 37(3), 225-229. https://doi.org/10.1016/ S0144-8617(98)00064-2

Lehtonen, P. and Hurme, R. (1994). Liquid chromatographic determination of sugars in beer by evaporative light scattering detector. Journal of the Institute of Brewing, 100(5), 343-346. https:// doi.org/10.1002/j.2050-0416.1994.tb00834.x

Macrae, R. and Dick, J.J. (1981). Analysis of carbohydrates using mass detector. Journal of Chromatography, 210(1), 138-145. https:// doi.org/10.1016/S0021-9673(00)91190-7

Macrae, R., Trugo, L.C. and Dick, J. (1982). The mass detector: a new detection system for carbohydrate and lipid analyses. Chromatographia, 15, 476-478. https://doi.org/10.1007/BF02261612

Madigan, D., McMurrough, I. and Smyth, M.R. (1996). Application of gradient ion chromatography with pulsed electrochemical detection to the analysis of carbohydrates in brewing. Journal of American Society of Brewing Chemists, 54(1), 45-49. https:// doi.org/10.1094/ASBCJ-54-0045

Mauriello, G., Marino, R., D’Auria, M., Cerone, G. and 
Rana, G.L. (2001). Determinazione dei componenti volatili dei tartufi lucani. Micologia Italiana, 30(3), 11-29. [In Italian].

Mauriello, G., Marino, R., D’Auria, M., Cerone, G. and Rana, G.L. (2004). Determination of volatile organic compounds from truffles via SPME-GC-MS. Journal of Chromatographic Science, 42(6), 299305. https://doi.org/10.1093/chromsci/42.6.299

McLinn, C.A., Collier, J.E. and Constant, M.D. (1994). Evaluation of cation exchange HPLC columns for the separation of carbohydrates in wort and beer. Journal of American Society of Brewing Chemists, 52(2), 65-70. https://doi.org/10.1094/ASBCJ-520065

Nikolov, Z.L., Meagher, M.M. and Reilly, P.J. (1985). High-performance liquid chromatography of disaccharides on amine-bonded silica columns. Journal of Chromatography, 319, 51-57. https:// doi.org/10.1016/S0021-9673(01)90538-2

Nogueira, L.C., Silva, F., Ferreira, I.M.P.L.V.O. and Trugo, L.C. (2005). Separation and quantification of beer carbohydrates by high-performance liquid chromatography with evaporative light scattering detection. Journal of Chromatography A, 1065(2), 207-210. https://doi.org/10.1016/ j.chroma.2004.12.074

Okeyo, P.D. and Snow, N.H. (1998). Analysis of estrogens and anabolic steroids by SPME with onfiber derivatization and GC-MS. Journal of Microcolumn Separation, 10(7), 551-556. https:// doi.org/10.1002/(SICI)1520-667X(1998) 10:7<551::AID-MCS1>3.0.CO;2-F

Pawliszyn, J. (1997). Solid phase micro-extraction: theory and practice. New York: VCH.

Rajakyla, E. (1986). Use of reversed-phase chromatography in carbohydrate analysis. Journal of Chromatography, 353, 1-12. https://doi.org/10.1016/ S0021-9673(01)87070-9

Torto, N., Buttler, T., Gordon, L., Marko-Varga, G., Stalbrand, H. and Tjerneld, F. (1995). Monitoring of enzimatic hydrolysis of ivory nut mannan using online microdialysis sampling and anion-exchange chromatography with integrated pulsed electrochemical detection. Analitica Chimica Acta, 313(1-2), 15-24. https://doi.org/10.1016/0003-2670 (95)00071-7

Wei, Y. and Ding, M. (2000). Analysis of carbohydrates in drinks by high-performance liquid chromatography with a dynamically modified amino column and evaporative light scattering detection. Journal of Chromatography A, 904(1), 113-117. https://doi.org/10.1016/S0021-9673(00)00909-2 